\title{
STRUKTUR DAN DISTRIBUSI PENDAPATAN PETANI PENANGKAR TEH (Camellia sinensis L. O. Kuntze) GAMBUNG 7 DI DESA CUKANGKAWUNG KECAMATAN SODONGHILIR KABUPATEN TASIKMALAYA
}

\section{STRUCTURE AND DISTRIBUTION OF INCOME OF FARMER TEA (CAMELLIA SINENSIS L. O. KUNTZE) GAMBUNG 7 IN CUKANGKAWUNG VILLAGE, SODONGHILIR DISTRICT, TASIKMALAYA REGENCY}

\author{
DEDE ROHMAN*, AGUS YUNIAWAN ISYANTO, MUHAMAD NURDIN YUSUF \\ Fakultas Pertanian, Universitas Galuh \\ *Email : dederohman@gmail.com
}

\begin{abstract}
ABSTRAK
Penelitian ini bertujuan untuk mengetahui: 1). pendapatan petani penangkar teh; 2). struktur pendapatan; dan 3). distribusi pendapatan petani penangkar teh Gambung 7 di Desa Cukangkawung Kecamatan Sodonghilir Kabupaten Tasikmalaya. Jenis penelitian ini adalah penelitian kualitatif dengan metode studi kasus. Pengambilan responden dilakukan dengan sensus kepada 10 petani penangkar teh. Data primer dan data sekunder dikumpulkan melalaui observasi, wawancara, studi literatur dan dokumentasi. Pendapatan petani dianalissi dengan analisis biaya, penerimaan dan pendapatan serta kelayakan usaha dianalisis menggunakan R/C ratio. Struktur pendapatan dianalisis dengan analisis struktur pendapatan dan distribusi pendapatan dengan Indeks Gini Ratio. Hasil penelitian menunjukkan bahwa 1) Pendapatan rata-rata petani penangkar teh Gambung 7 sebesar Rp. 214.484.104,- per tahun yang bersal dari penerimaan sebesar Rp. 529.607 .250 dan biaya total Rp. 352.598.146,- dengan R/C ratio sebesar 1,$53 ; 2$ ). Struktur pendapatan petani berasal dari kontribusi sektor pertanian $69,36 \%$ yang berasal dari usaha penangkaran teh $43,91 \%$, sektor non budiaya 14,28 $\%$ dan sektor usahatani non penangkar $11,18 \%$ dan dari sektor non pertanian sebesar 30,64 persen; dan 3). Distribusi pendapatan petani penangkar teh di Desa Cukangkawung Kecamatan Sodonghilir menunjukkan ketimpangan rendah dengan nilai Indeks Gini Ratio sebesar 0,260.
\end{abstract}

Kata kunci: pendapatan penangkar teh, struktur dan distribusi pendapatan,.

\section{ABSTRACT}

This study aims to determine: 1). income of tea breeder farmers; 2). income structure; and 3). income distribution of Gambung 7 tea breeder farmers in Cukangkawung Village, Sodonghilir District, Tasikmalaya Regency. This type of research is qualitative research with a case study method. Respondents were taken by census to 10 tea breeders. Primary data and secondary data were collected through observation, interviews, literature study and documentation. Farmers' income is analyzed by analyzing costs, revenues and income as well as business feasibility analyzed using the $R /$ $C$ ratio. Income structure is analyzed by analysis of income structure and income distribution with the Gini Ratio Index. The results showed that 1) The average income of Gambung 7 tea breeder farmers was $R p$. 214,484,104, - per year from the revenue of $R p .529,607,250$ and a total cost of $R p$. $352,598,146$, - with an $R / C$ ratio of $1.53 ; 2$ ). The income structure of farmers comes from the contribution of the agricultural sector $69.36 \%$ which comes from the tea breeding business $43.91 \%$, the non-cultivating sector $14.28 \%$ and the non-breeder farming sector $11.18 \%$ and from the nonagricultural sector by 30.64\%; and 3). The income distribution of tea breeder farmers in Cukangkawung Village, Sodonghilir District shows low inequality with a Gini Ratio Index value of 0.260 .

Key Words : income tea growers, income structure and distribution 


\section{PENDAHULUAN}

Komoditas teh (Camellia sinensis L. O. Kuntze) memiliki peranan penting dalam perekonomian masyarakat Kabupaten Tasikmalaya, sebagai sumber pendapatan, penyerapan tenaga kerja, mendorong agroindustri dan pelestarian lingkungan. Tahun 2019, Kabupaten Tasikmalaya memberikan kontribusi sebesar 16,64\% terhadap total produksi Jawa Barat. tahun 2018, luas perkebunan teh rakyat di Kabupaten Tasikmalaya 9,039 hektar dengan jumlah produksi teh 13,238 ton (Diperpakan Kabupaten Tasikmalaya, 2019). Sentra pengembangan teh terletak di Kecamatan Bojonggambir, Sodonghilir dan Taraju.

Kecamatan Sodonghilir mempunyai luas teh rakyat 2.522 hektar. Pada tahun 2019, produksi teh di Kecamatan Sodonghilir sebesar 1.608 ton yang dihasilkan dari luas lahan 1.027 hektar tanaman menghasilkan dari total luas tanam 2.097 hektar. Luas lahan dan produksi teh di Kecamatan Sodonghilir cenderung terus menurun karena belum dapat diatasinya masalah yang dihadapi, seperti : rendahnya produktivitas karena belum menggunakan benih unggul, rendahnya harga yang diterima petani, masih rendahnya kualitas SDM, terbatasnya penguasaan teknologi pengolahan produk (GAP dan GMP)., rendahnya kemampuan permodalan, kurangnya keterkaitan petani teh dari mulai hulu sampai ke hilir, belum adanya usaha peningkatan nilai tambah terhadap produk teh, belum berperannya kelompok tani teh, koperasi dan lembaga keuangan lainnya.

Upaya peningkatan produksi dan produktivitas tanaman teh telah dilakukan dengan berbagai macam cara, diantaranya dengan cara penanaman klon unggul yang diikuti dengan tindakan kultur teknis yang tepat. Salah satunya memulai dari pembibitan dengan menanam teh klon Gambung (GMB) 7. Menurut Dalimonthe (2013), besarnya faktor yang berperan dalam peningkatan produksi dan produktivitas tanaman teh adalah faktor genetik klon yang digunakan (25\%), faktor lingkungan (15\%), teknik budidaya $(35 \%)$ dan aspek manajerial (25\%).

Usaha penangkaran bibit teh di Desa Cukangkawung Kecamatan Sodonghilir sudah dikenal dan dipraktekkan oleh petani sejak lama dengan teknologi dan sistem manajemen yang sederhana serta penuh kearifan lokal. Petani biasanya membangun penangkaran skala mikro untuk menanami lahan yang mereka miliki saja. Hal tersebut tentunya akan berdampak terhadap pendapatan dan kesejahteraan keluarga petani penangkar teh. 
Dampak adanya penangkaran teh terhadap kehidupan masyarakat Desa Cukangkawung sekitar dilihat dari dampak sosial dan dampak ekonomi, terutama pada pendapatan dan penyerapan tenaga kerja masyarakat yang tinggal di sekitar penangkaran. Menurut Sukarno et. al., (2015), pola distribusi pendapatan petani selama kurun waktu 35 tahun terakhir ternyata cukup rnerata dengan arah perkembangan dan tingkat distribusi pendapatan yang menunjukkan trend semakin membaik.

Trimo, et. al., (2017) menjelaskan rata-rata pendapatan petani teh pertahun di Kabupaten Cianjur Rp. 6.084.300, Bandung Rp. 12.848.700, Garut Rp. 10.351.700 dan Kabupaten Tasikmalaya sebesar Rp. 5.615.146 (Lukman et.al., 2017). Umumnya penangkar juga berprofesi sebagai petani teh. Namun sebagian tidak hanya terfokus pada kegiatan usaha teh saja sebagai upaya untuk meningkatkan pendapatan. Hal tersebut dikarenakan sebagian petani merupakan petani dengan skala kepemilikan lahan yang sempit. Dalam rangka meningkatkan pendapatan, penagkar teh umumnya memiliki kegiatan tambahan seperti bertani padi, usahatani sayur, peternakan, buruh tani, berdagang dan lain sebagainya. Jenis kegiatan non-pertanian setiap penangkar tidaklah sama tetapi sangat bervariasi tergantung dari sumberdaya yang dimiliki.

Berdasarkan hal di atas, maka usaha penangkaran teh perlu digarap dengan serius. Usahatani tersebut perlu dilakukan dengan mengelola komponen input dan output secara terintegrasi dengan memperhatikan aspek ekologi, sosial dan ekonomi agar keberlanjutannya tetap terjaga. Aspek ekologi ditekankan pada dukungan sumberdaya lahan dan air serta lingkungan. Aspek sosial ditekankan pada dampak sosial yang ditimbulkan dari keberadaan penagkaran teh terhadap masyarakat, sedangkan aspek ekonomi ditekankan terhadap distribusi dan kontribusinya dalam memberikan manfaat ekonomi bagi petani dalam bentuk peningkatan pendapatan.

\section{METODE PENELITIAN}

Jenis penelitian ini adalah kuantitatif dengan metode studi kasus. Data primer diperoleh dari hasil wawancara dari petani penangkar teh. Data sekunder diperoleh dari studi literatur, instansi dan bahan publikasi yang ada kaitannya dengan penelitian. Penarikan sampel menggunakan metode sensus, yaitu mengambil seluruh petani penangkar teh klon Gambung 7 yang berada di Desa Cukangkawung Kecamatan Sodonghilir sebanyak 10 orang. 
Pendapatan petani dianalissi dengan analisis biaya, penerimaan dan pendapatan dengan rumus Suratiyah (2006):

$$
\pi=\mathrm{TR}-\mathrm{TC}
$$

Dimana:

$\pi=$ Pendapatan bersih/keuntungan

$\mathrm{TR}=$ Total penerimaan $($ total revenue $)$

$\mathrm{TC}=$ Total biaya $($ total cost $)$

Struktur pendapatan dihitung dengan analisis struktur pendapatan :

$$
\mathbf{P r t}=\mathbf{P}_{\text {Penangkat teh }}+\mathbf{P}_{\text {On farm }}+\mathbf{P}_{\text {Off farm }}+\mathbf{P}_{\text {Non }}
$$

Dimana :

Prt $=$ Pendapatan petani $(\mathrm{Rp} / \mathrm{th})$

$\mathrm{P}_{\text {penangkar teh }}=$ Pendapatan penangkaran teh $(\mathrm{Rp} / \mathrm{th})$

$\mathrm{P}_{\text {On farm }}=$ Pendapatan usahatani non penangkar (Rp/th)

$\mathrm{P}_{\text {off farm }}=$ Pendapatan di luar kegiatan budidaya (Rp/th)

$\mathrm{P}_{\text {Non farm }}=$ Pendapatan dari usaha non pertanian (Rp/th)

Distribusi pendapatan dengan Indeks Gini Ratio.

$$
\begin{gathered}
\mathrm{GK}=1-\Sigma \cdot\left(\mathrm{Xi}_{+1}-\mathrm{Xi}\right)\left(\mathrm{Yi}+\mathrm{Yi}_{+1}\right), \text { atau } \\
\mathrm{GK}=1-\Sigma \cdot \mathrm{Fi}\left(\mathrm{Yi}_{+1}+\mathrm{Yi}\right)
\end{gathered}
$$

Dimana:

GK $=$ Gini koefisien

$\mathrm{Xi}=$ Proporsi jumlah petani kumulatif kelas ke I $\mathrm{Yi}=$ Proporsi jumlah pendapatan petani kumulatif dalam kelas ke i.

\section{HASIL DAN PEMBAHASAN}

\section{Analisis Pendapatan Petani Penangkar Teh}

Biaya total diperoleh dengan menjumlahkan antara biaya tetap dengan biaya tidak tetap. Biaya-biaya yang dikeluarkan petani dalam usaha penangkaran teh terdiri dari biaya tetap atau fixed cost (FC) dan biaya tidak tetap atau variable cost (VC). Biaya tetap terdiri dari biaya sewa lahan, penyusutan alat-alat pertanian dan bunga modal. Biaya tidak tetap terdiri dari biaya pengambilan stek, pupuk, pestisida, naungan, pos jaga, tenaga kerja dan sarana produksi penunjang lainnya serta bunga modal. 
Tabel 1. Biaya Total Usahatani Penangkaran Teh

\begin{tabular}{|c|c|c|c|}
\hline \multirow{2}{*}{ No } & \multirow{2}{*}{ Komponen Usahatani } & \multicolumn{2}{|c|}{ Usaha Penangkaran Teh } \\
\hline & & Jumlah (Rp//periode) & Persen $(\%)$ \\
\hline A & Biaya Tetap (FC) & & \\
\hline 1 & Sewa lahan & 1.545 .000 & 0,44 \\
\hline 2 & Pajak & 154.500 & 0,04 \\
\hline 3 & Penyusutan alat & 1.998 .700 & 0,57 \\
\hline 4 & Bunga modal & 277.365 & 0,08 \\
\hline & Jumlah (1) & 3.975.565 & 1,13 \\
\hline $\mathrm{B}$ & Biaya Tidak Tetap (VC) & & \\
\hline 1 & Bambu & 11.650 .000 & 3,32 \\
\hline 2 & Paranet & 55.160 .000 & 15,73 \\
\hline 3 & Pembuatan pos jaga & 3.750 .000 & 1,07 \\
\hline 4 & Stek teh & 97.335 .000 & 27,76 \\
\hline 5 & Polybag & 14.256 .000 & 4,07 \\
\hline 6 & Tanah (topsoil+subsoil) & 4.540 .000 & 1,29 \\
\hline 7 & MPHP & 9.328 .000 & 2,66 \\
\hline 8 & Pupuk Urea & 401.375 & 0,11 \\
\hline 9 & Pupuk TSP & 695.200 & 0,20 \\
\hline 10 & Pupuk KCL & 695.000 & 0,20 \\
\hline 11 & Tawas & 2.957 .500 & 0,84 \\
\hline 12 & Pupuk daun & 2.820 .000 & 0,80 \\
\hline 13 & Dithane $80 \mathrm{WP}$ & 3.864 .000 & 1,10 \\
\hline 14 & Fastac 15 EC & 1.173 .000 & 0,33 \\
\hline 15 & Winder $100 \mathrm{EC}$ & 3.060 .000 & 0,87 \\
\hline 16 & Samite 135 & 2.880 .000 & 0,82 \\
\hline 17 & Buldok 25 EC & 1.600 .000 & 0,46 \\
\hline 18 & Tenaga Kerja & 108.135 .000 & 30,31 \\
\hline 19 & Bunga modal & 24.322 .506 & 6,90 \\
\hline & Jumlah (2) & 348.622 .581 & $\mathbf{9 8 , 8 7}$ \\
\hline $\mathrm{C}$ & Biaya Total (TC) $(3=1+2)$ & 352.598 .146 & 100,00 \\
\hline
\end{tabular}

Tabel 1. menunjukkan bahwa biaya total penangkaran teh per usahatani per periode yaitu sebesar Rp. 352.598.146,yang terdiri dari biaya tetap sebesar $\mathrm{Rp}$. 3.975.565 atau 1,13 persen dan biaya tidak tetap sebesar Rp. 348.622.581,-atau 98,87 persen.

Biaya tetap rata-rata usaha penangkaran teh per usahatani per periode yaitu sebesar Rp. 3.975.565,- atau 1,13 persen yang terdiri dari biaya sewa lahan sebesar Rp. 1.545.000,- atau 0,44 persen, pajak lahan sebesar Rp. 154.500,- atau 0,04 persen, biaya penyusutan alat pertanian sebesar Rp. 1.998.700,- atau 0,57 persen dan bunga modal sebesar Rp. 277.365 atau 0,08 persen.

Biaya tidak tetap rata-rata untuk usaha penangkaran teh per usahatani per periode yaitu sebesar Rp. 346.612.331,- 
atau 98,87 persen. Tenaga kerja dan pengambilan teh menempati proporsi paling tinggi yaitu sebesar Rp 108.135.000 dan Rp 97.335.000 atau 30,31 persen dan 27,76 persen.

\section{Pendapatan dan Kelayakan Usaha}

Pendapatan petani merupakan selisih antara penerimaan total dengan biaya total usahatani. Panen bibit dilakukan pada usia 8-9 bulan. Presentase bibit hidup berkisar antara 70-80 persen. Bibit mati antara 20-30 persen. Sementara bibit yang dijual atau bibit normal berkisar antara 70-75 persen dan sisanya adalah bibit afkir. Bibit yang dijual sebanyak 196.470 pohon. harga rata-rata yang diterima petani sebesar Rp. 2.785,- per pohon (borongan)

Tabel 2. Produksi, Harga, Biaya, Penerimaan, Pendapatan dan R/C Ratio

\begin{tabular}{|c|c|c|c|}
\hline No & $\begin{array}{l}\text { Komponen } \\
\text { Usahatani }\end{array}$ & Jumlah (Rp) & Keterangan \\
\hline 1 & Populasi stek & 278.100 & Tanam \\
\hline 2 & Bibit dijual & 190.164 & Bibit dijual \\
\hline 3 & $\begin{array}{l}\text { Bibit tidak } \\
\text { dijual }\end{array}$ & 87.936 & $\begin{array}{l}\text { Biit afkir }+ \\
\text { terserang H/P }\end{array}$ \\
\hline 4 & Harga jual & 2.785 & Jual borongan \\
\hline 5 & Penerimaan & 529.607 .250 & $\begin{array}{l}\text { Penerimaan } \\
\text { total (TR) }\end{array}$ \\
\hline 6 & Biaya & 352.598 .146 & Biaya total \\
\hline 7 & Pendapatan & 177.009.104 & TR-TC \\
\hline 8 & $\mathrm{R} / \mathrm{C}$ ratio & 1,53 & $\mathrm{TR} / \mathrm{TC}$ \\
\hline
\end{tabular}

Tabel 2. menunjukkan bahwa ratarata penerimaan total pada usahatani penangkaran teh sebesar Rp. 529.607.250 dengan biaya total produksi rata-rata sebesar Rp. 352.598.146 sehingga menghasilkan pendapatan rata-rata sebesar Rp. 177.009.104 hektar per periode produksi.

Nilai R/C ratio pada usahatani penangkaran teh sebesar 1,53 artinya setiap Rp. 1,00 yang dikeluarkan dalam usahatani penangkaran teh dapat menghasilkan penerimaan sebesar Rp. 1,53. Maka dengan demikian dapat disimpulkan usahatani penangkaran teh layak untuk diusahakan dan menguntungkan. Hal ini sejalan dengan pendapat Soekartawi (1995) apabila nilai $\mathrm{R} / \mathrm{C}$ ratio > 1 maka layak diusahakan.

\section{Struktur Pendapatan Petani Penangkar} Teh

Sumber pendapatan petani penangkar teh di Desa Cukangkawung berasal dari sektor pertanian (on farm dan off farm) dan non pertanian (non farm). 
Tabel 3. Struktur Pendapatan Penangkar Teh

\begin{tabular}{lrr}
\hline \multicolumn{1}{c}{ Sumber Pendapatan } & $\begin{array}{c}\text { Pendapatan } \\
\text { (Rp/tahun) }\end{array}$ & $\begin{array}{c}\text { Kontri-busi } \\
(\%)\end{array}$ \\
\hline SEKTOR PERTANIAN & & \\
Usaha penangkaran teh & $\mathbf{1 7 7 . 0 0 9 . 1 0 4}$ & $\mathbf{4 3 , 9 1}$ \\
Usahatani non penangkar & $\mathbf{4 5 . 0 7 5 . 0 0 0}$ & $\mathbf{1 1 , 1 8}$ \\
Petani teh & 22.000 .000 & 5,46 \\
Peternak & 3.500 .000 & 0,87 \\
Petani padi & 4.575 .000 & 1,13 \\
Petani hortikultura & 15.000 .000 & 3,72 \\
Usahatani non budidaya & $\mathbf{5 7 . 5 0 0 . 0 0 0}$ & $\mathbf{1 4 , 2 8}$ \\
Pengusaha pabrik teh & 50.000 .000 & 12,40 \\
Buruh tani teh & 7.500 .000 & 1,86 \\
SEKTOR NONPERTANIAN & $\mathbf{1 2 3 . 5 0 0 . 0 0 0}$ & $\mathbf{3 0 , 6 4}$ \\
Pensiunan & 35.000 .000 & 8,68 \\
Pengusaha mebeul & 25.000 .000 & 6,20 \\
PNS/ Guru/Honorer & 40.000 .000 & 9,92 \\
Pedagang sembako & 15.000 .000 & 3,72 \\
Perangkat Desa (BPD) & 3.500 .000 & 0,87 \\
Pengelola BUMDES & 5.000 .000 & 1,24 \\
\hline JUMLAH & $\mathbf{4 0 3 . 0 8 4 . 1 0 4}$ & $\mathbf{1 0 0 , 0 0}$ \\
\hline
\end{tabular}

Tabel 3. menunjukkan bahwa peran sektor pertanian mendominasi struktur pendapatan petani sebesar 69,36 persen atau sebesar Rp. 403.084.104, yang terdiri sumber pendapatan usaha penangkaran teh, usahatani non penangkar dan usahatani non budidaya. Sementara sisanya berasal dari sektor non pertanian sebesar 30,64 persen.

Sumber pendapatan usaha penangkaran teh memiliki kontribusi sebesar 43,91 persen atau sebesar Rp. 177.009.104 per usahatani per tahun. Sumber pendapatan tersebut hampir separuh dari pendapatan total petani, dan juga menjadi sumber pendapatan tertinggi dibandingkan sumber pendapatan lainnya. Artinya, penangkaran teh merupakan sumber pendapatan utama bagi rumah tangga petani penangkar teh di Desa Cukangkawung Kecamatan Sodonghilir Kabupaten Tasikmalaya

\section{Distribusi Pendapatan Petani Penangkar}

Teh

Distribusi pendapatan merupakan salah satu ukuran untuk menunjukan tingkat pendapatan yang diterima masyarakat. 
Tabel 4. Tingkat Pendapatan Penangkar Teh

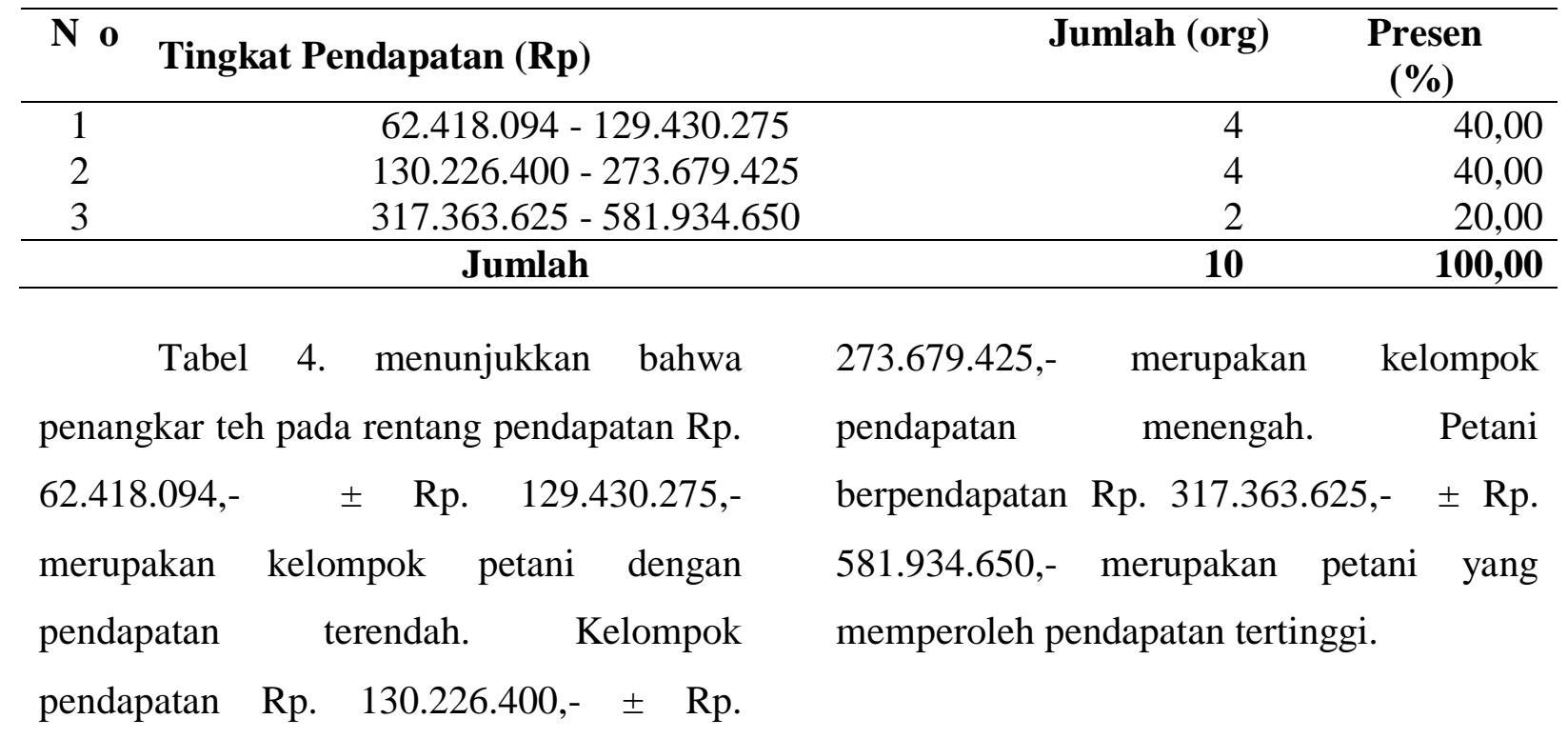

\section{Tabel 5. Distribusi Pendapatan Penangkar Teh}

\begin{tabular}{lrrr}
\hline Golongan & Total Pendapatan (Rp) & $\begin{array}{c}\text { Rata-rata Pendapatan } \\
(\mathbf{R p})\end{array}$ & Presen (\%) \\
\hline $40 \%$ terendah & 411.442 .419 & $102.860 .604,69$ & 19,18 \\
$40 \%$ menengah & 834.100 .350 & $208.525 .087,50$ & 38,89 \\
$20 \%$ tertinggi & 899.298 .275 & $449.649 .137,50$ & 41,93 \\
\hline \multicolumn{1}{c}{ Jumlah } & $\mathbf{2 . 1 4 4 . 8 4 1 . 0 4 4}$ & $\mathbf{1 0 0 , 0 0}$ \\
\hline
\end{tabular}

Tabel menunjukkan bahwa 4 pendapatan menengah dengan total $\mathrm{Rp}$. penangkar teh termasuk golongan 40\% 834.100.350,-. dan 2 petani termasuk dalam pendapatan terendah dengan total golongan $20 \%$ pendapatan tertinggi-.

pendapatan sebesar Rp. 411.442.419,-, 4 petani masuk dalam golongan $40 \%$

Tabel 6. Indeks Gini Rasio Petani Penangkar Teh

\begin{tabular}{|c|c|c|c|c|}
\hline $\begin{array}{c}\text { Kelompok } \\
\text { Pendapatan (P i) }\end{array}$ & $\begin{array}{c}\text { Presen }(\%) \\
\text { (Qi) }\end{array}$ & $\begin{array}{c}\text { \% Komulatif ( } \\
-1)\end{array}$ & $(\mathbf{Q i}+\mathbf{Q i}-\mathbf{1})$ & $\begin{array}{c}\mathbf{P i}(\mathbf{Q i}+\mathbf{Q i}- \\
1) / 100\end{array}$ \\
\hline $40 \%$ terendah & 19,18 & 19,18 & 19,18 & 0,077 \\
\hline $40 \%$ menengah & 38,89 & 58,07 & 77,25 & 0,309 \\
\hline $20 \%$ tertinggi & 41,93 & 100,00 & 177,25 & 0,355 \\
\hline Jumlah & 100,00 & & & 0,740 \\
\hline & & \multicolumn{2}{|c|}{ Gini Rasio } & 0,260 \\
\hline
\end{tabular}


nilai Indeks Gini Ratio sebesar 0,260. Angka Rasio Gini tersebut menunjukkan bahwa distribusi pendapatan petani penangkar teh di Desa Cukangkawung Kecamatan Sosonghilir berada pada tingkat ketimpangan rendah. Hal ini sesuai dengan kriteria Todaro dan Smith, (2003) yang menyatakan nilai Indeks Gini kurang dari 0,4 menunjukkan ketimpangan rendah; artinya kemerataan pendapatan petani penangkar teh sudah cukup baik walaupun ada beberapa petani memiliki pendapatan yang lebih besar atau berbeda dengan petani lainnya.

Untuk melihat visual distribusi pendapatan dilihat melalaui Kurva Lorenz.

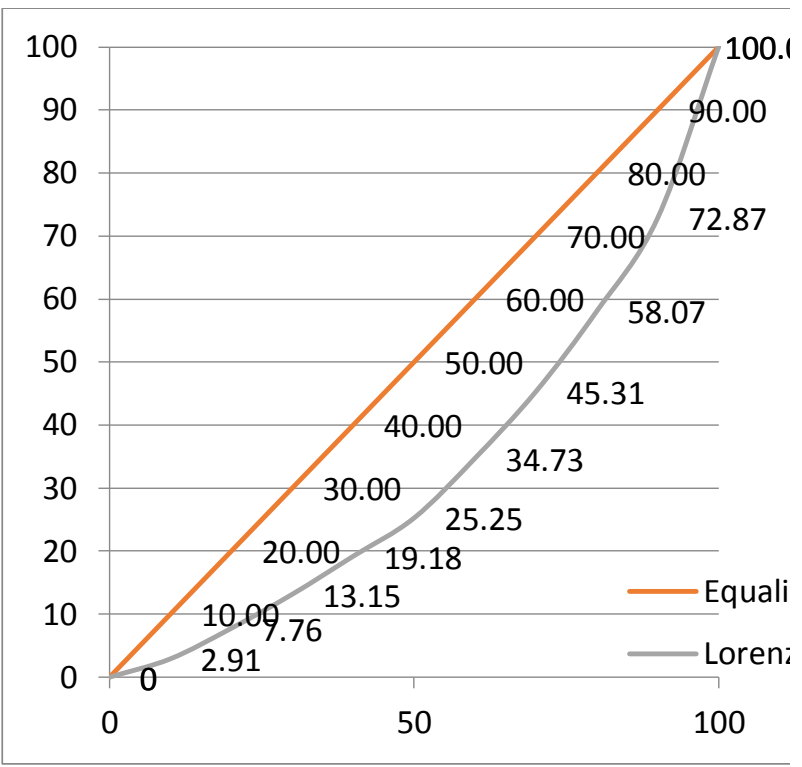

\section{KESIMPULAN DAN SARAN}

\section{Kesimpulan}

Berdasarkan hasil dan pembahasan, maka penelitian ini dapat diambil kesimpulan berikut:

1) Pendapatan rata-rata petani penangkar teh Gambung 7 di Desa Cukangkawung Kecamatan Sodonghilir sebesar Rp. 214.484.104,- per tahun yang bersal dari penerimaan total rata-rata sebesar $\mathrm{Rp}$. 529.607.250 dan biaya total rata-rata sebesar Rp. 352.598.146,- dengan nilai $\mathrm{R} / \mathrm{C}$ ratio sebesar 1,53.

2) Struktur pendapatan petani penangkar teh berasal dari sektor pertanian dan non pertanian. Sektor pertanian berkontribusi sebesar $69,36 \%$ yang berasal dari usaha penangkaran teh berkontribusi sebesar $43,91 \%$, sektor non budiaya sebesar 14,28 persen dan sektor usahatani non penangkar sebesar $11,18 \%$ dan sisanya berasal dari sektor non pertanian sebesar 30,64 persen.

3) Distribusi pendapatan petani penagkar teh menunjukkan ketimpangan rendah dengan nilai Indeks Gini Ratio sebesar 0,260 menunjukkan tidak terjadi ketimpangan pendapatan pada petani penangkar teh di di Desa Cukangkawung Kecamatan Sodonghilir Kabupaten Tasikmalaya. 


\section{Saran}

1) Setiap sumber pendapatan berperanan penting dalam menyumbang pendapatan rumahtangga petani, sehingga perlu lebih dikembangkan untuk mencukupi kebutuhan hidup, meningkatkan pendapatan dan kesejahteraan petani penangkar teh.

2) Adanya pengembangan sumber pendapatan lain akan membawa perbaikan dalam struktur pendapatan rumahtangga petani, kecenderungan nilai Indeks Gini mengecil mendekati nol.

3) Perlunya penelitian lebih lanjut

\section{DAFTAR PUSTAKA}

Dalimonthe, S. L. 2013. Implikasi Pemetikan Secara Mekanis terhadap Produksi, Mutu Hasil Olahan dan Kesehatan Tanaman Teh. Prosiding Pertemuan Teknis Teh Nasional 1999. PPTK, Bandung.
Diperpakan Kabupaten Tasikmalaya. 2019. Identifikasi Komoditi Perkebunan (Teh) di Kabupaten Tasikmalaya. Dinas Pertanian, Pangan dan Perikanan Kabupaten Tasikmalaya, Tasikmalaya.

Lukman. A, Sutandi, A. Khursatul Munibah. 2017. Arahan Pengembangan Perkebunan Teh (Camellia Sinensis (L.) O. Kuntze) Rakyat di Kabupaten Tasikmalaya. Journal of Regional and Rural Development Planning. Juni 2017, 1 (2):158-173.

Sukarno, T. D, D. Mardiningsih, T. Dalmiyatun. 2015. Kontribusi Perusahaan terhadap Pendapatan dan Penyerapan Tenaga Kerja Masyarakat Lokal di Perkebunan Teh PT. Rumpun Sari Medini. Hal : $1-12$.

Suratiyah, 2006. Ilmu Usahatani. Penebar Swadaya. Jakarta.

Trimo. L, Sri Fatimah, dan Endah Djuwendah. 2017. Kajian Pengembangan Agroindustri Berbasis Teh Rakyat. Jurnal Rekayasa Hijau. Juli 2017. No.2 Vol. I : 136-145. 